\section{Imatinib dose reduction in major molecular response of chronic myeloid leukemia: results from the German Chronic Myeloid Leukemia-Study IV}

Christian Michel, ${ }^{1 *}$ Andreas Burchert,,${ }^{1, *}$ Andreas Hochhaus ${ }^{2}$ Susanne Saussele, ${ }^{3}$ Andreas Neubauer, ${ }^{1}$ Michael Lauseker, ${ }^{4}$ Stefan W. Krause, ${ }^{5}$ Hans-Jochem Kolb, ${ }^{6}$ Dieter Kurt Hossfeld, ${ }^{7}$ Christoph Nerl, ${ }^{8}$ Gabriela M. Baerlocher, ${ }^{9}$ Dominik Heim, ${ }^{10}$ Tim H Brümmendorf, ${ }^{11}$ Alice Fabarius, ${ }^{3}$ Claudia Haferlach, ${ }^{12}$ Brigitte Schlegelberger, ${ }^{13}$ Leopold Balleisen, ${ }^{14}$ Maria-Elisabeth Goebeler, ${ }^{15}$ Mathias Hänel, ${ }^{16}$ Anthony Ho, ${ }^{17}$ Jolanta Dengler, ${ }^{18}$ Christiane Falge, ${ }^{19}$ Robert Möhle, ${ }^{20}$ Stephan Kremers, ${ }^{21}$ Michael Kneba, ${ }^{22}$ Frank Stegelmann, ${ }^{23}$ Claus-Henning Köhne,$^{24}$ Hans-Walter Lindemann, ${ }^{25}$ Cornelius F. Waller, ${ }^{26}$ Karsten Spiekermann, ${ }^{6}$ Wolfgang E. Berdel, ${ }^{27}$ Lothar Müller, ${ }^{28}$ Matthias Edinger, ${ }^{29}$ Jiri Mayer, ${ }^{30}$ Dietrich W. Beelen, ${ }^{31}$ Martin Bentz, ${ }^{32}$ Hartmut Link ${ }^{33}$ Bernd Hertenstein, ${ }^{34}$ Roland Fuchs, ${ }^{11}$ Martin Wernli, ${ }^{35}$ Frank Schlegel, ${ }^{36}$ Rudolf Schlag ${ }^{37}$ Maike de Wit, ${ }^{38}$ Lorenz Trümper, ${ }^{39}$ Holger Hebart, ${ }^{40}$ Markus Hahn, ${ }^{41}$ Jörg Thomalla, ${ }^{42}$ Christof Scheid, ${ }^{43}$ Philippe Schafhausen, ${ }^{7}$ Walter Verbeek ${ }^{44}$ Michael J. Eckart, ${ }^{45}$ Winfried Gassmann, ${ }^{46}$ Michael Schenk, ${ }^{47}$ Peter Brossart ${ }^{48}$ Thomas Wündisch, ${ }^{1}$ Thomas Geer, ${ }^{49}$ Stephan Bildat, ${ }^{50}$ Erhardt Schäfer, ${ }^{51}$ Joerg Hasford, ${ }^{4}$ Rüdiger Hehlmann ${ }^{3}$ and Markus Pfirrmann ${ }^{4}$

${ }^{1}$ Universitätsklinikum Gießen und Marburg, Campus Marburg, Klinik für Hämatologie, Onkologie und Immunologie, Philipps Universität Marburg, Germany; ${ }^{2}$ Klinik fü $\square n n e r e$ Medizin II, Hämatologie und Internistische Onkologie, Jena, Germany; ${ }^{3} I I$. Medizinische Klinik, Medizinische Fakultät Mannheim, University Heidelberg, Mannheim, Germany; ${ }^{4}$ Institut für Medizinische Informationsverarbeitung, Biometrie und Epidemiologie, Ludwig-Maximilians-Universität München, Munich, Germany; ${ }^{5}$ Medizinische Klinik 5 , Universitätsklinikum, Erlangen, Germany; ${ }^{6}$ Medizinische Klinik III, Universität München, Germany; ${ }^{7}$ Medizinische Klinik, Universitätsklinikum Eppendorf, Hamburg, Germany; ${ }^{8}$ Klinikum Schwabing, Munich, Germany; 'Inselspital, Bern, Switzerland;

${ }^{10}$ Universitätsspital, Basel, Switzerland; ${ }^{11} \mathrm{RWTH}$, Aachen, Germany; ${ }^{12} \mathrm{MLL}$, Munich, Germany; ${ }^{13}$ Institut für Humangenetik, MHH, Hannover, Germany; ${ }^{14} \mathrm{Ev}$. Krankenhaus, Hamm, Germany; ${ }^{15}$ Comprehensive Cancer Center Mainfranken und Medizinische Klinik II, Zentrum für Innere Medizin, Würzburg, Germany; ${ }^{16} \mathrm{Klinik}$ für Innere Medizin 3, Chemnitz, Germany; ${ }^{17}$ Medizinische Klinik V, Universität Heidelberg, Germany; ${ }^{18}$ Onkologische Schwerpunktpraxis, Heilbronn, Germany; ${ }^{19}$ Medizinische Klinik 5, Klinikum Nürnberg-Nord, Germany; ${ }^{20}$ Medizinische Abteilung 2, Universitätsklinikum, Tübingen, Germany; ${ }^{21}$ Caritas Krankenhaus, Lebach, Germany; ${ }^{22}$ 2. Medizinische Klinik und Poliklinik, Universitätsklinikum Schleswig-Holstein, Kiel, Germany; ${ }^{23}$ Klinik für Innere Medizin 3, Universitätsklinikum, Ulm, Germany; ${ }^{24}$ Universitätsklinik für Onkologie und Hämatologie, Oldenburg, Germany; ${ }^{25}$ St Marien-Hospital, Hagen, Germany; ${ }^{26}$ Innere Medizin 1, Universitätsklinikum, Freiburg, Germany; ${ }^{27}$ Medizinische Klinik A, Universitätsklinikum, Münster, Germany; ${ }^{28}$ Onkologie Leer Unter Ems, Leer, Germany; ${ }^{29}$ Klinik und Poliklinik für Innere Medizin 3, Universitätsklinikum, Regensburg, Germany; ${ }^{30}$ Masaryk University Hospital, Brno, Czech Republic; ${ }^{31} \mathrm{Klinik}$ für Knochenmarktransplantation, Essen, Germany; ${ }^{32}$ Medizinische Klinik 3, Städtisches Klinikum, Karlsruhe, Germany; ${ }^{33}$ Hematology, Medical Oncology, Kaiserslautern, Germany; ${ }^{34} 1$. Medizinische Klinik, Klinikum Bremen Mitte, Bremen, Germany; ${ }^{35}$ Kantonsspital, Aarau, Switzerland; ${ }^{36}$ St Antonius-Hospital, Eschweiler, Germany; ${ }^{37}$ Hämatologische-Onkologische Schwerpunktpraxis, Würzburg, Germany; ${ }^{38}$ Klinik für Innere Medizin II, Hämatologie, Onkologie und Palliativmedizin, Vivantes Klinikum Neukölln, Berlin, Germany; ${ }^{39} \mathrm{Klinik}$ für Hämatologie und medizinische Onkologie, Universitätsmedizin, Göttingen, Germany; ${ }^{40}$ Stauferklinikum Schwäbisch Gmünd, Mutlangen, Germany; ${ }^{41}$ Onkologie Zentrum, Ansbach, Germany; ${ }^{42}$ Praxisklinik für Hämatologie und Onkologie, Koblenz, Germany; ${ }^{43}$ Klinik 1 für Innere Medizin, Universitätsklinikum, Köln, Germany; ${ }^{44} \mathrm{Ambulante} \mathrm{Hämatologie} \mathrm{und} \mathrm{Onkologie,} \mathrm{Bonn,}$ Germany; ${ }^{45}$ Internistische Schwerpunktpraxis, Erlangen, Germany; ${ }^{46}$ St MarienKrankenhaus, Siegen, Germany; ${ }^{47}$ Barmherzige Brüder, Regensburg, Germany; ${ }^{48}$ Medizinische Klinik 3, Universität, Bonn, Germany; ${ }^{49}$ Diakonie, Schwäbisch Hall, Germany; ${ }^{50}$ Medizinische Klinik 2, Herford, Germany and ${ }^{51}$ Onkologische Schwerpunktpraxis, Bielefeld, Germany

${ }^{\star} \mathrm{CM}$ and $\mathrm{AB}$ contributed equally to this work.
Haematologica 2019

Volume 104(5):955-962

\section{Correspondence:}

ANDREAS BURCHERT

burchert@staff.uni-marburg.de

Received: September 23, 2018.

Accepted: November 22, 2018.

Pre-published: December 4, 2018.

doi:10.3324/haematol.2018.206797

Check the online version for the most updated information on this article, online supplements, and information on authorship \& disclosures: www.haematologica.org/content/104/5/955

\section{(C)2019 Ferrata Storti Foundation}

Material published in Haematologica is covered by copyright. All rights are reserved to the Ferrata Storti Foundation. Use of published material is allowed under the following terms and conditions:

https://creativecommons.org/licenses/by-nc/4.0/legalcode. Copies of published material are allowed for personal or internal use. Sharing published material for non-commercial purposes is subject to the following conditions: https://creativecommons.org/licenses/by-nc/4.0/legalcode, sect. 3. Reproducing and sharing published material for commercial purposes is not allowed without permission in writing from the publisher. 
tandard first-line therapy of chronic myeloid leukemia is treatment with imatinib. In the randomized

S German Chronic Myeloid Leukemia-Study IV, more potent BCR-ABL inhibition with $800 \mathrm{mg}$ ("highdose') imatinib accelerated achievement of a deep molecular remission. However, whether and when a de-escalation of the dose intensity under high-dose imatinib can be safely performed without increasing the risk of losing deep molecular response is unknown. To gain insights into this clinically relevant question, we analyzed the outcome of imatinib dose reductions from $800 \mathrm{mg}$ to $400 \mathrm{mg}$ daily in the Chronic Myeloid Leukemia-Study IV. Of the 422 patients that were randomized to the $800 \mathrm{mg}$ arm, 68 reduced imatinib to $400 \mathrm{mg}$ after they had achieved at least a stable major molecular response. Of these 68 patients, $61(90 \%)$ maintained major molecular remission on imatinib at $400 \mathrm{mg}$. Five of the seven patients who lost major molecular remission on the imatinib standard dose regained major molecular remission while still on $400 \mathrm{mg}$ imatinib. Only two of 68 patients had to switch to more potent kinase inhibition to regain major molecular remission. Importantly, the lengths of the intervals between imatinib high-dose treatment before and after achieving major molecular remission were associated with the probabilities of maintaining major molecular remission with the standard dose of imatinib. Taken together, the data support the view that a deep molecular remission achieved with high-dose imatinib can be safely maintained with standard dose in most patients. Study protocol registered at clinicaltrials.gov 00055874.

\section{Introduction}

Approved first-line therapies of chronic myeloid leukemia (CML) are the tyrosine kinase inhibitors (TKIs) imatinib, dasatinib, nilotinib and bosutinib. ${ }^{1.5}$ Imatinib led to distinctively improved progression-free and overall survival of chronic phase CML patients as compared with previous conventional treatment standards in CML. ${ }^{6,7}$ Second-generation TKIs, such as nilotinib and dasatinib, but also a higher dose of imatinib (800 mg/day), induce deep molecular response (MR) faster ${ }^{8,9}$ and in a larger proportion of patients. ${ }^{10,11}$ As a consequence, deep molecular remission (an essential eligibility criterion for TKI discontinuation) can be achieved earlier and in more patients when compared to imatinib standard dose. ${ }^{12,13}$ However, the benefit of pursuing highly-potent BCR-ABL-kinase inhibition once deep MR has been achieved is less clear. Moreover, for those patients in deep MR, which (for whatever reason) require long-term treatment, the tolerability and prevention of organ damage through clinically relevant and potentially irreversible side effects, such as pulmonary hypertension, diabetes, hypercholesterinemia, and cardiovascular morbidity become the most important priority. ${ }^{14 \cdot 17}$ Thus, if highpotency BCR-ABL inhibition is not needed to sustain remission or improve survival, then the risk of potentially harmful side effects from second- or third-generation TKI must be weighed against the long-term safety of using imatinib, ${ }^{18-}$ ${ }^{20}$ especially when also considering that generic imatinib is more cost effective. By analyzing the outcome of $800 \mathrm{mg}$ to $400 \mathrm{mg}$ imatinib dose reductions performed in at least stable major molecular remission (MMR) within the randomized German CML-Study IV, ${ }^{8,21}$ we aimed to address the clinically important questions of in which patients and at what time after initiation of strong BCR-ABL inhibition with $800 \mathrm{mg}$ imatinib less potent $\mathrm{BCR}-\mathrm{ABL}$ inhibition with standard dose imatinib is sufficient to maintain stable MMR.

\section{Methods}

\section{Patients and Chronic Myeloid Leukemia-Study IV protocol}

All patients investigated in this study were treated within the randomized German CML-Study IV. ${ }^{8,21}$ Imatinib monotherapy at
$800 \mathrm{mg} /$ day was one of the five arms in this trial. The study protocol was registered at clinicaltrials.gov 00055874 . Randomization took place from July 2002 through March 2012. During a pilotphase of 3 years, only high-risk patients according to the Euro score $^{22}$ were randomized to imatinib $800 \mathrm{mg} /$ day. In 2005, imatinib $800 \mathrm{mg} /$ day was started as a full study arm.

To avoid selection bias towards high-risk patients, in this retrospective analysis, only patients randomized from 2005 were evaluated.

\section{Definition of high-dose imatinib treatment}

Imatinib at a dose of $800 \mathrm{mg} /$ day for at least 6 months was classified as high-dose therapy. Six months was chosen because the presence of MMR after 6 months significantly increased the probabilities of patients going on to achieve deep MR later. ${ }^{8} \mathrm{~A}$ highdose treatment interval began with the first dose of $800 \mathrm{mg} /$ day and ended at the time of imatinib dose reduction to $400 \mathrm{mg} /$ day. An intermittent $600 \mathrm{mg} /$ day interval which directly preceded or followed a high-dose treatment interval with $800 \mathrm{mg} /$ day was still considered high-dose treatment because the effective median dose of imatinib in the $800 \mathrm{mg}$ arm was seen to be only $600 \mathrm{mg}$ in the CML-Study IV.

The molecular analyses are described in the Online Supplementary Appendix.

\section{Statistical analysis}

Survival without loss of MMR was defined as the time between the start of reduced imatinib therapy with $400 \mathrm{mg}$ /day either until loss of MMR or until the date of the last evaluation of MR status with the date linkable to the reduction period, as defined in the Online Supplementary Methods. Probabilities of molecular relapsefree survival (RFS) were estimated by the Kaplan-Meier method. The association between a variable and molecular RFS was assessed by Cox regression. ${ }^{23}$ For identification of cutoffs, the minimal $P$-value approach was used while assuming that the smallest group should contain at least $10 \%$ of patients. ${ }^{24}$ Bootstrap resampling and kernel density estimation were carried out to assess the stability of a cutoff. ${ }^{25,26}$

Point estimates are given together with their 95\% confidence intervals $(95 \% \mathrm{CI})$. In the case of the hazard ratios (HR), for estimation of the $95 \% \mathrm{CI}$, the profile likelihood was used and $P$-values were calculated from the likelihood ratio test. All analyses are descriptive and exploratory. Apart from the minimal $P$-value 
approach, the significance level of the two-sided $P$-value was 0.05 for all statistical tests. Analyses were carried out with SAS v.9.4 or R v.3.4.3.

\section{Ethical approval}

The CML-Study IV was performed in accordance with the Declaration of Helsinki, and was approved by the central ethics committee of the Medizinische Fakultaet Mannheim and the local ethics committees of all participating centers. Written informed consent was obtained from all patients prior to entering the CMLStudy IV.

\section{Results}

\section{Imatinib dose reduction in the $\mathbf{8 0 0} \mathbf{m g}$ cohort of the} Chronic Myeloid Leukemia-Study IV

Of 1551 patients with newly diagnosed chronic phase CML, 422 were randomly assigned to $800 \mathrm{mg}$ imatinib per day. Of these, two patients violated CML-Study IV inclu- sion criteria, ten were part of the pilot study, and a further ten were excluded from this analysis due to missing treatment data (see the CONSORT flow diagram in Figure 1).

Of the remaining 400 patients randomized to $800 \mathrm{mg}$ imatinib, 92 patients had never received imatinib 800 $\mathrm{mg} /$ day and 163 patients never achieved MMR within the imatinib $800 \mathrm{mg} /$ day interval. Of the remaining 145 patients, 39 had never reduced the $800 \mathrm{mg} /$ day dose or had no observation time after dose reduction. A further 21 had an $800 \mathrm{mg} /$ day interval of less than 6 months (i.e. not high-dose imatinib by our definition). Two patients were excluded because they had more than 6 weeks without any therapy between ending $800 \mathrm{mg} /$ day imatinib and recommencing $400 \mathrm{mg} / \mathrm{day}$. Eight patients were not considered because treatment with $400 \mathrm{mg}$ /day lasted for less than 6 months. After exclusion of a further seven patients who had not been monitored by the central molecular diagnostic laboratory of the CML-Study IV, 68 patients were evaluable for our analyses.

Data entry was closed on July 21, 2015.

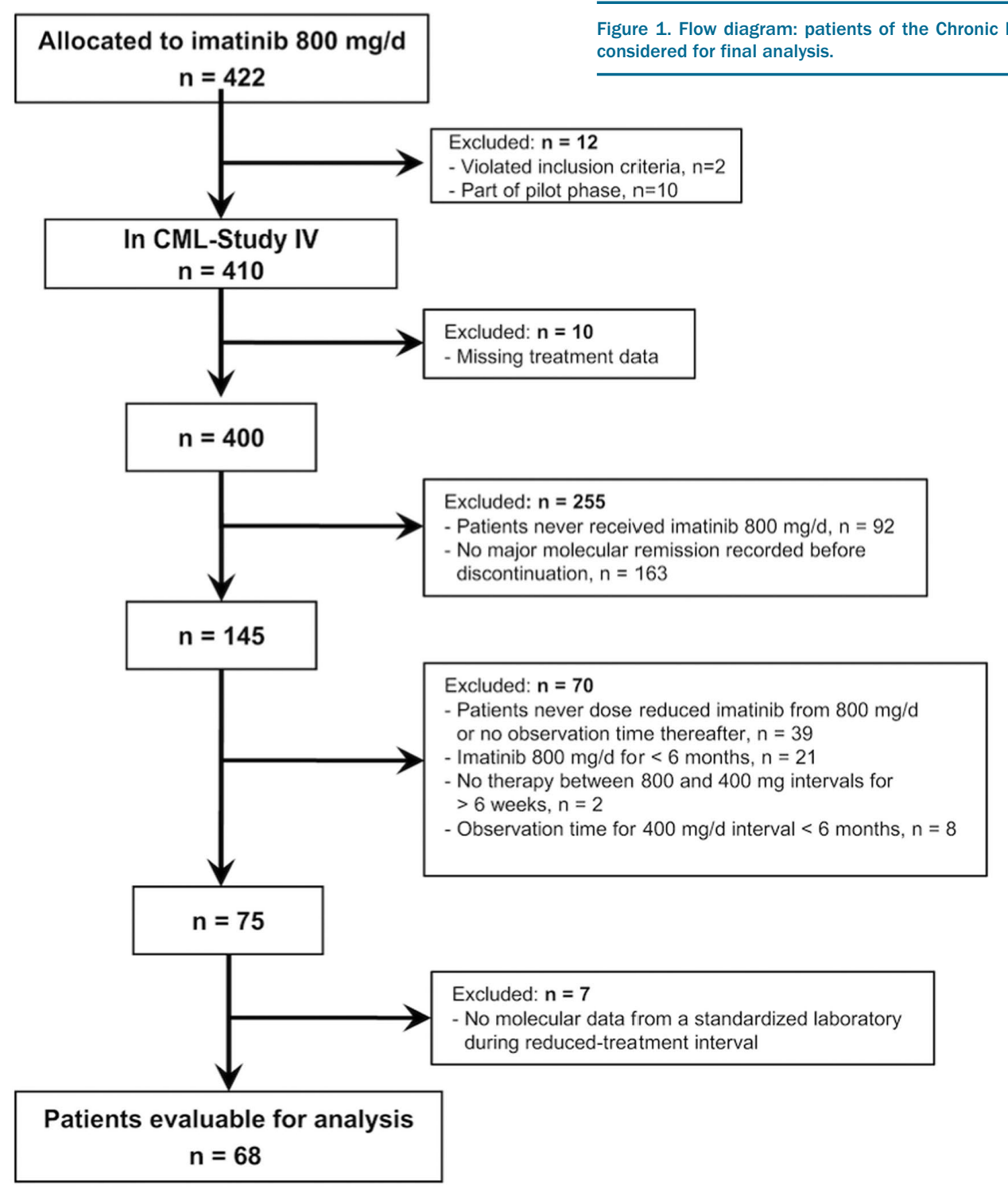


Table 1. Univariate Cox regression estimating the influence on relapse-free survival after reduction to imatinib at $400 \mathrm{mg}$.

\begin{tabular}{|c|c|c|c|c|c|c|c|}
\hline Variable & $\begin{array}{l}\text { n / Loss } \\
\text { of MMR }\end{array}$ & $\begin{array}{l}\text { Estimation of } \\
\text { coefficient } \beta\end{array}$ & $\begin{array}{l}\text { Standard } \\
\text { deviation of } \\
\text { estimated } \beta\end{array}$ & $\begin{array}{l}\text { Hazard } \\
\text { ratio }\end{array}$ & $\begin{array}{l}\text { Lower } \\
95 \% \text { Cl } \\
\text { limit for } \\
\text { hazard } \\
\text { ratio }\end{array}$ & $\begin{array}{c}\text { Upper } \\
95 \% \text { CI } \\
\text { ratio limit } \\
\text { for hazard } \\
\text { ratio }\end{array}$ & $P$ \\
\hline
\end{tabular}

Variables recorded at diagnosis

\begin{tabular}{|c|c|c|c|c|c|c|c|}
\hline Age (years) & $68 / 7$ & -0.001 & 0.03 & 1.00 & 0.94 & 1.06 & 0.97 \\
\hline Gender & $68 / 7$ & & & & & & 0.28 \\
\hline Male & $48 / 6$ & baseline & - & - & - & - & - \\
\hline Female & $20 / 1$ & -1.04 & 1.08 & 0.36 & 0.02 & 2.08 & - \\
\hline Spleen size below costal margin $(\mathrm{cm})$ & $68 / 7$ & 0.16 & 0.06 & 1.17 & 1.03 & 1.31 & 0.02 \\
\hline White blood cell count $\left(\times 10^{9} / \mathrm{L}\right) / 100$ & $68 / 7$ & 1.01 & 0.25 & 2.76 & 1.69 & 4.73 & 0.0001 \\
\hline Blasts in peripheral blood (\%) & $68 / 7$ & 0.24 & 0.11 & 1.27 & 0.99 & 1.55 & 0.06 \\
\hline Eosinophils in peripheral blood (\%) & $68 / 7$ & 0.19 & 0.07 & 1.21 & 1.02 & 1.37 & 0.03 \\
\hline Basophils in peripheral blood (\%) & $68 / 7$ & 0.09 & 0.07 & 1.10 & 0.93 & 1.25 & 0.24 \\
\hline Platelet count $\left(\mathrm{x} 10^{9} / \mathrm{L}\right) / 1000$ & $68 / 7$ & -2.44 & 2.35 & 1.00 & 0.00 & 3.40 & 0.24 \\
\hline Sokal score & $68 / 7$ & & & & & & 0.57 \\
\hline Low risk & $29 / 2$ & baseline & - & - & - & - & - \\
\hline Intermediate risk & $27 / 3$ & 0.60 & 0.91 & 1.82 & 0.30 & 13.79 & - \\
\hline High risk & $12 / 2$ & 1.05 & 1.01 & 2.87 & 0.34 & 24.15 & - \\
\hline Euro score & $68 / 7$ & & & & & & 0.04 \\
\hline Low risk & $30 / 1$ & baseline & - & - & - & - & - \\
\hline Intermediate risk & $34 / 4$ & 1.42 & 1.12 & 4.13 & 0.61 & 80.86 & - \\
\hline High risk & $4 / 2$ & 3.04 & 1.23 & 20.98 & 1.99 & 454.17 & - \\
\hline EUTOS score & $68 / 7$ & & & & & & 0.01 \\
\hline Low risk & $62 / 4$ & baseline & - & - & - & - & - \\
\hline High risk & $6 / 3$ & 2.26 & 0.77 & 9.56 & 1.88 & 43.50 & - \\
\hline ELTS score & $68 / 7$ & & & & & & 0.01 \\
\hline Low risk & $44 / 1$ & baseline & - & - & - & - & - \\
\hline Intermediate risk & $19 / 4$ & 2.30 & 1.12 & 9.98 & 1.48 & 195.25 & - \\
\hline High risk & $5 / 2$ & 3.17 & 1.23 & 23.71 & 2.25 & 513.27 & - \\
\hline \multicolumn{8}{|c|}{ Variables recorded under treatment and their influence after stopping treatment at $800 \mathrm{mg} / \mathrm{day}$} \\
\hline Time with $800 \mathrm{mg}$ dosage, months & $68 / 7$ & -0.05 & 0.03 & 0.95 & 0.891 & 0.998 & 0.04 \\
\hline Time from start of $800 \mathrm{mg}$ until MMR, months & $68 / 7$ & 0.13 & 0.05 & 1.14 & 1.02 & 1.27 & 0.02 \\
\hline Time from MMR until end of $800 \mathrm{mg}$, months & $68 / 7$ & -0.15 & 0.07 & 0.86 & 0.72 & 0.96 & 0.0006 \\
\hline
\end{tabular}

CI: Confidence Interval; MMR: major molecular remission; EUTOS: European Treatment and Outcome Study; ELTS: EUTOS long-term survival.

Patients' characteristics are shown in Online Supplementary Table S1. Median age was 52 years and $71 \%$ of the 68 patients were male.

\section{Treatment course of patients with imatinib dose reduction to $400 \mathrm{mg}$}

Twenty-five of the 68 patients on high-dose imatinib $(37 \%)$ started their primary treatment directly with 800 $\mathrm{mg} /$ day (first treatment interval). Forty patients (59\%) increased to $800 \mathrm{mg} /$ day after a first period of $400 \mathrm{mg}$ imatinib. Three patients only started the $800 \mathrm{mg}$ imatinib dose later.

Median time on high-dose imatinib therapy was 31 months (range: 6-98 months) for the 68 patients who later reduced imatinib treatment to $400 \mathrm{mg}$ (Online Supplementary Table S1). In this cohort, the median dura- tion of treatment with $400 \mathrm{mg} /$ day after dose reduction was 34 months (range: 6-78 months). For 53 out of 68 patients $(78 \%)$, this was the last reported treatment and dose. Five patients $(7 \%)$ eventually stopped any TKI therapy following imatinib dose reduction to $400 \mathrm{mg}$. In one patient, no information regarding treatment after dose reduction to $400 \mathrm{mg}$ was available. The remaining 9 out of 68 patients $(13 \%)$ received a more potent ABL-kinase inhibition: $600 \mathrm{mg}$ imatinib ( $\mathrm{n}=1), 800 \mathrm{mg}$ imatinib $(\mathrm{n}=5)$, nilotinib $(n=2)$, or dasatinib $(n=1)$.

\section{Molecular relapse-free survival after imatinib dose reduction to $400 \mathrm{mg}$}

Seven of 68 patients experienced a loss of MMR during the reduction interval (Figure 2). This resulted in a 1-year molecular relapse-free survival (RFS) of 90\% (95\% CI: 81- 


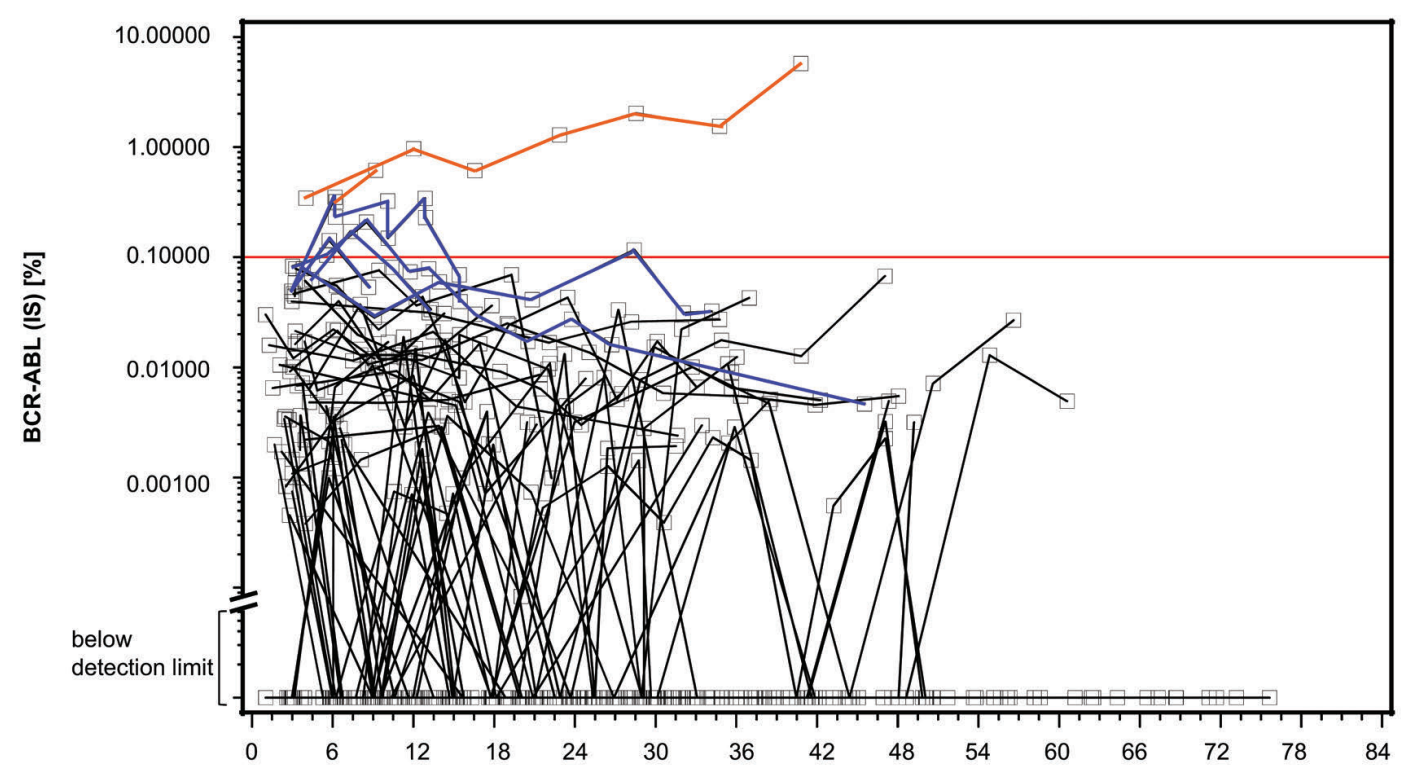

Time in months after reduction to $400 \mathrm{mg} /$ day

Figure 2. Courses of BCR-ABL (IS) in 68 patients with imatinib dose reduction. Results below the horizontal red line represent at least major molecular response (MMR). Sixty-one patients have never lost MMR (courses with black lines). Five patients with loss of MMR regained MMR while continuing with reduced imatinib dose at $400 \mathrm{mg} /$ day (blue lines). Two patients with loss of MMR did not regain MMR while on the lower imatinib dose and were switched to nilotinib or imatinib at $600 \mathrm{mg} /$ day, respectively (orange lines).

96\%). With only one MMR loss occurring later than 12 months after dose reduction, the 3-year molecular RFS was $88 \%$ (95\% CI: 77-94\%) (Figure 3). However, MMR loss was only temporary in five of the seven patients; these patients regained MMR while still on the lower 400 mg imatinib dose. Only two patients with MMR loss were switched to more potent ABL-inhibition with nilotinib or $600 \mathrm{mg}$ imatinib to regain MMR (Figure 2). It is worthy of note that, at the time of stopping high-dose treatment, 43 of 68 patients were at least in MR4, 33 of them even at least in MR4.5. Of the 43 patients, 10 lost MR4 at some point; none lost MMR.

\section{Clinical variables and high-dose imatinib treatment durations prior to and after achieving major molecular response were associated with probabilities of relapse-free survival}

Of the clinical variables evaluated at diagnosis, larger spleen size below costal margin (HR: 1.17, 95\%CI: 1.031.31; $P=0.02$ ), higher white blood cell count (WBC) (HR: 2.76, 95\%CI: 1.69-4.73; $P=0.0001)$, and a higher percentage of eosinophils (HR: 1.21, 95\% CI: 1.02-1.37; $P=0.03$ ) were significantly associated with probabilities of lower RFS (Table 1). Furthermore, the high-risk groups according to the Euro and the European Treatment and Outcome Study (EUTOS) scores, as well as the intermediate- and high-risk groups according to the EUTOS long-term survival (ELTS) score, suggested significantly worse molecular RFS than their corresponding low-risk groups.

The longer the total treatment time at $800 \mathrm{mg} / \mathrm{day}$, the higher were the probabilities of RFS (HR: 0.95 , 95\% CI: 0.891-0.998; $P=0.04$ ). However, as in the EURO-SKI study, which analyzed TKI discontinuation, the main focus was to investigate treatment time after dividing this time inter- val into the time of high-dose treatment before and after achievement of $M R^{27}$

Four of the 68 patients had already achieved MMR with $400 \mathrm{mg}$ imatinib/ day prior to the high-dose treatment interval. The median time to achieving MMR was 5 months (range: 0-23 months) (Online Supplementary Table S1). The longer the time with treatment at $800 \mathrm{mg} /$ day until achieving $M M R$, the lower were the probabilities of RFS (HR: 1.14, 95\% CI: 1.02-1.27; $P=0.02)$. Using the minimum $P$-value approach, with the prerequisite that the smallest group contained at least $10 \%$ of the patients, a cutoff of 13 months was observed $\left(\mathrm{P}_{\text {adiusted }}=0.007\right)$. This cutoff was confirmed with bootstrap resampling: in 1000 bootstrap samples, the cutoff of 13 months was most frequently chosen. For the 56 patients who had an MMR within 13 months while on treatment at $800 \mathrm{mg} /$ day, the probability of molecular RFS 12 months after stopping high-dose treatment was 94\% (95\% CI: 84-98\%), whereas it was 74\% [95\%CI: 39-91\%; HR: 7.39 (95\% CI: $1.62-$ 37.74)] for the 12 patients who had an MMR after more than 13 months of high-dose treatment (Figure 4A).

The median time from achievement of MMR until dose reduction to $400 \mathrm{mg}$ was 23 months (range: 0-93 months) (Online Supplementary Table S1). The longer the time with MMR while on treatment at $800 \mathrm{mg} /$ day, the higher were the probabilities of RFS (HR: 0.86, 95\% CI: 0.72-0.96; $P=0.0006)$. Using the minimum $P$-value approach, with the prerequisite that the smallest group contained at least $10 \%$ of the patients, a cutoff of 8.5 months was observed $\left(\mathrm{P}_{\text {adiusted }}=0.011\right)$. This cutoff was confirmed with bootstrap resampling: in 1000 bootstrap samples, the cutoff of 8.5 months was most frequently chosen. For the 53 patients who were more than 9 months on high-dose treatment after achievement of $M M R$, the probability of molecular 


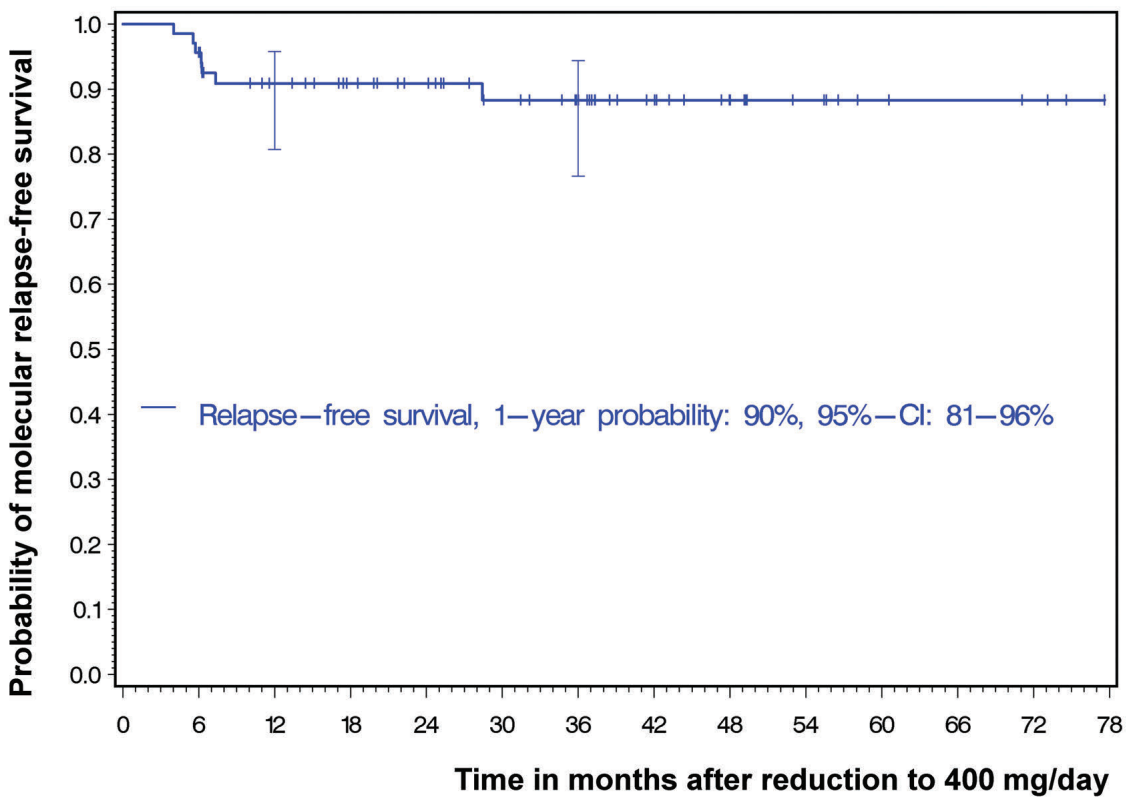

Figure 3. Probabilities of molecular relapse-free survival after dose reduction to imatinib at $400 \mathrm{mg} /$ day. At 12 and 36 months, horizontal crossbars indicate the upper and lower limit of the 95\% confidence interval $(\mathrm{Cl})$ for the estimated probability.

\section{Number of patients still at risk ( $n$ ) at different months of observation}

\begin{tabular}{|l|c|c|c|c|c|c|c|}
\hline Months & $\mathbf{0}$ & $\mathbf{1 2}$ & $\mathbf{2 4}$ & $\mathbf{3 6}$ & $\mathbf{4 8}$ & $\mathbf{6 0}$ & $\mathbf{7 2}$ \\
\hline Patients at risk, $\mathrm{n}$ & 68 & 52 & 41 & 29 & 14 & 5 & 3 \\
\hline
\end{tabular}

RFS 12 months after stopping high-dose treatment was $98 \%$ (95\% CI: 87-99\%), whereas it was 65\% [95\% CI: $34-$ 84\%; HR: 0.096 (95\% CI: 0.014-0.449)] for the 15 patients who were only on high-dose treatment for 9 months or less after achieving MMR (Figure 4B).

\section{Discussion}

The concept of starting CML therapy upfront with more potent BCR-ABL inhibition than is achievable with $400 \mathrm{mg}$ imatinib has been introduced to prevent early disease progression and induce deep MR faster and more effectively. ${ }^{2}$ However, it is not known in which patients and when after the initiation of a more potent BCR-ABL kinase inhibition (second/third-generation TKI or $800 \mathrm{mg}$ imatinib) a deep MR can be maintained after de-escalation to $400 \mathrm{mg}$ imatinib.

Trials investigating dose reductions are rare. In the DESTINY study, the dose of second-generation TKIs was reduced to half the respective standard dose. ${ }^{28}$ However, in terms of BCR-ABL inhibitory potency, even reduced second-generation TKI doses such as those used in the DESTINY trial demonstrate significantly more BCR-ABL inhibition than $400 \mathrm{mg}$ imatinib. To our knowledge, a controlled switch from highly potent BCR-ABL kinase inhibition with $800 \mathrm{mg}$ imatinib or second/third-generation TKI to $400 \mathrm{mg} /$ day imatinib has never been performed prospectively.

On the other hand, a reduction of imatinib treatment intensity to $400 \mathrm{mg}$ is frequently required in patients who achieve a deep MR but experience toxicities or acquire/ have worsening comorbidities of a type that prevents the further use of second-generation TKI. Furthermore, those patients with deep MR who relapse after TKI cessation or who do not wish to discontinue their TKI, and therefore require life-long TKI therapy, are all candidates for a dose de-escalation to imatinib $400 \mathrm{mg}$.

Here, we studied the stability of a deep MR in patients of the German CML-Study IV who had MMR or better response for at least 6 months when they reduced imatinib from $800 \mathrm{mg}$ to $400 \mathrm{mg}$ per day. We wished to gain insight into whether treatment duration with $800 \mathrm{mg}$ imatinib has an impact on subsequent maintenance of deep $\mathrm{MR}$ with imatinib at the $400 \mathrm{mg}$ standard dose. We also searched for clinical variables associated with maintenance of at least MMR after dose reduction of imatinib.

We found that, if BCR-ABL-monitoring once every three months is ensured, imatinib dose reduction from $800 \mathrm{mg}$ to $400 \mathrm{mg} / \mathrm{day}$ in patients with stable MMR did not compromise efficacy or risk sustained MMR in most patients, as only two of seven patients who had lost MMR on $400 \mathrm{mg}$ imatinib required a rescue treatment with more potent BCR-ABL-kinase inhibitors. This also suggests that if standard dose imatinib treatment and BCR-ABL monitoring are ensured, a single loss of $\mathrm{MMR}$ might not require immediate re-intensification of TKI treatment. ${ }^{29}$ Secondly, despite only 7 events, statistical modeling suggested that achieving an MMR within 13 months under $800 \mathrm{mg}$ imatinib, as well as staying on $800 \mathrm{mg}$ imatinib for at least 9 months after achievement of MMR, are both good predictors of a successful continuous MMR maintenance under the standard imatinib dose of $400 \mathrm{mg}$.

Interestingly, with the exception of WBC count, all other prognostic markers identified for a successful imatinib dose reduction have previously also been reported as predictors for treatment-free remission (TFR). ${ }^{7,22,27,30}$ Based on this, it is tempting to speculate that the biology of TFR 
A

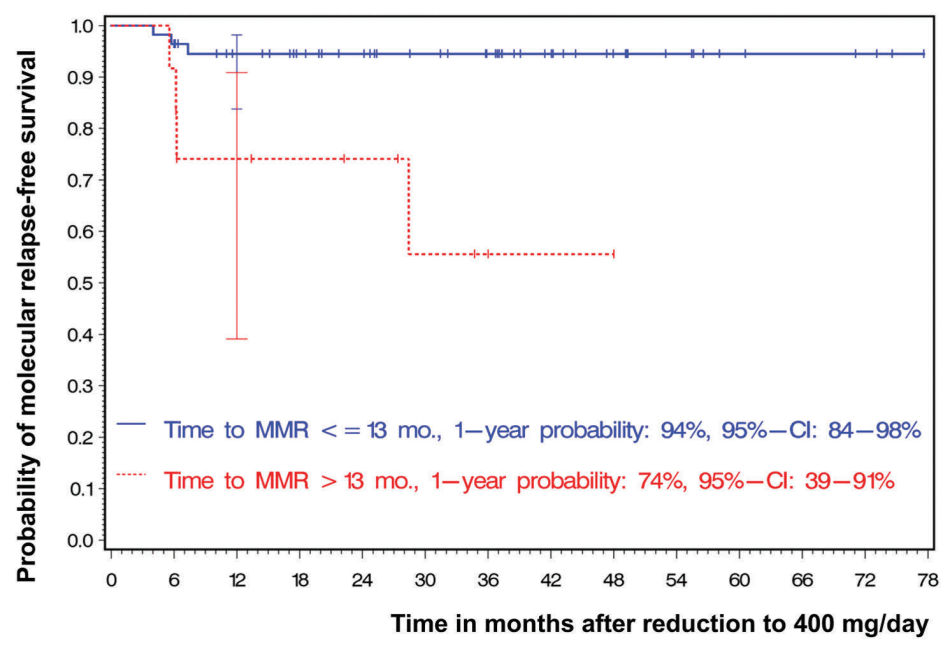

Number of patients still at risk $(n)$ at different months of observation

\begin{tabular}{|l|c|c|c|c|c|c|c|}
\hline Months & $\mathbf{0}$ & $\mathbf{1 2}$ & $\mathbf{2 4}$ & $\mathbf{3 6}$ & $\mathbf{4 8}$ & $\mathbf{6 0}$ & $\mathbf{7 2}$ \\
\hline Time to MMR <= 13 mo., $\mathrm{n}$ & 56 & 45 & 36 & 27 & 13 & 5 & 3 \\
\hline Time to MMR > 13 mo., $\mathrm{n}$ & 12 & 7 & 5 & 2 & 1 & 0 & 0 \\
\hline
\end{tabular}

B

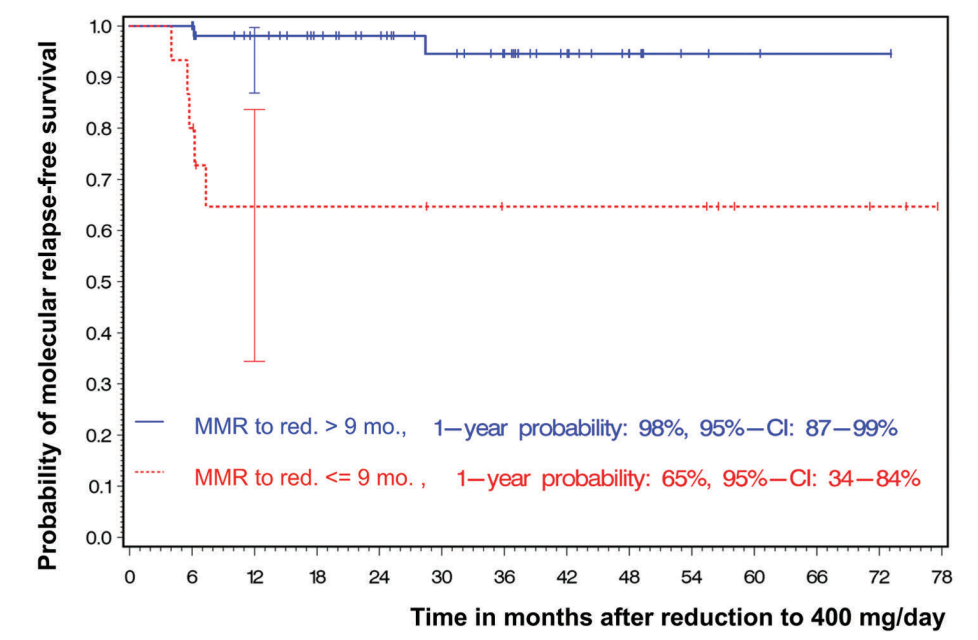

Number of patients still at risk ( $\mathrm{n}$ ) at different months of observation

\begin{tabular}{|l|c|c|c|c|c|c|c|}
\hline Months & $\mathbf{0}$ & $\mathbf{1 2}$ & $\mathbf{2 4}$ & $\mathbf{3 6}$ & $\mathbf{4 8}$ & $\mathbf{6 0}$ & $\mathbf{7 2}$ \\
\hline MMR to reduction (red.) $>9$ mo., $\mathrm{n}$ & 53 & 44 & 33 & 23 & 8 & 2 & 1 \\
\hline MMR to reduction (red.) $<=9$ mo., $\mathrm{n}$ & 15 & 8 & 8 & 6 & 6 & 3 & 2 \\
\hline
\end{tabular}

B

MR to reduction (red.) <= 9 mo., $n$
Figure 4. Factors influencing the probabilities of molecular relapse-free survival after imatinib dose reduction to $400 \mathrm{mg} /$ day. (A) Impact of time to major molecular response (MMR) and molecular relapsefree survival. (B) Impact of interval between MMR and imatinib dose reduction and molecular relapsefree survival. At 12 months (mo), horizontal crossbars indicate the upper and lower limit of the 95\% confidence interval $(\mathrm{Cl})$ for the estimated probability. 
106642); Deutsche José-Carreras Leukämiestiftung (DJCLS Hog/f, H06/04v, H03/01, R05/23, AH06.01); European Union (LSHC-CT-2004-503216); Novartis Oncology, Nürnberg (Drs G Gerhard, S Schaffert, A Jacob and U Haus);
Roche, Grenzach-Wyhlen; and Essex, Munich, Germany. We thank E Matzat, R Pleil-Lösch, I Stalljann, G Bartsch, C Sodan-Boyer, M Meckesheimer, U Böhm, A Gil and J Hehlmann for assistance.

\section{References}

1. Hehlmann R, Lauseker M, Saussele S, et al. Assessment of imatinib as first-line treatment of chronic myeloid leukemia: 10-year survival results of the randomized CML study IV and impact of non-CML determinants. Leukemia. 2017;31(11):2398-2406.

2. Hochhaus A, Larson RA, Guilhot F, et al. Long-Term outcomes of imatinib treatment for chronic myeloid leukemia. N Engl J Med. 2017;376(10):917-927.

3. Cortes JE, Saglio G, Kantariian HM, et al. Final 5-year study results of DASISION: The dasatinib versus imatinib study in treatment-naive chronic myeloid leukemia patients trial. J Clin Oncol. 2016; 34(20):2333-2340.

4. Hochhaus A, Saglio G, Hughes TP, et al. Long-term benefits and risks of frontline nilotinib vs imatinib for chronic myeloid leukemia in chronic phase: 5 -year update of the randomized ENESTnd trial. Leukemia. 2016;30(5):1044-1054

5. Cortes JE, Gambacorti-Passerini C, Deininger MW, et al. Bosutinib versus imatinib for newly diagnosed chronic myeloid leukemia: Results from the randomized BFORE trial. J Clin Oncol. 2018;36(3):231237.

6. Druker BJ, Guilhot F, O'Brien SG, et al. Five-year follow-up of patients receiving imatinib for chronic myeloid leukemia. N Engl J Med. 2006;355(23):2408-2417.

7. Pfirrmann M, Baccarani M, Saussele S, et al. Prognosis of long-term survival considering disease-specific death in patients with chronic myeloid leukemia. Leukemia. 2016;30(1):48-56.

8. Hehlmann R, Muller MC, Lauseker M, et al. Deep molecular response is reached by the majority of patients treated with imatinib, predicts survival, and is achieved more quickly by optimized high-dose imatinib: results from the randomized CMLstudy IV. J Clin Oncol. 2014;32(5):415-423.

9. Cortes JE, Baccarani M, Guilhot F, et al. Phase III, randomized, open-label study of daily imatinib mesylate $400 \mathrm{mg}$ versus 800 $\mathrm{mg}$ in patients with newly diagnosed, previously untreated chronic myeloid leukemia in chronic phase using molecular end points: tyrosine kinase inhibitor optimization and selectivity study. J Clin Oncol. 2010;28(3):424-430

10. Kantariian H, Shah NP, Hochhaus A, et al. Dasatinib versus imatinib in newly diagnosed chronic-phase chronic myeloid leukemia. N Engl J Med. 2010;
362(24):2260-2270

11. Saglio G, Kim DW, Issaragrisil $S$, et al Nilotinib versus imatinib for newly diagnosed chronic myeloid leukemia. $\mathrm{N}$ Engl J Med. 2010;362(24):2251-2259.

12. Saussele S, Richter J, Hochhaus A, Mahon FX. The concept of treatment-free remission in chronic myeloid leukemia. Leukemia. 2016;30(8):1638-1647.

13. Hochhaus A, Masszi T, Giles FJ, et al. Treatment-free remission following frontline nilotinib in patients with chronic myeloid leukemia in chronic phase: results from the ENESTfreedom study. Leukemia. 2017;31(7):1525-1531.

14. Steegmann JL, Baccarani M, Breccia M, et al. European LeukemiaNet recommendations for the management and avoidance of adverse events of treatment in chronic myeloid leukaemia. Leukemia. 2016; 30(8):1648-1671

15. Hochhaus A, Baccarani M, Deininger M, et al. Dasatinib induces durable cytogenetic responses in patients with chronic myelogenous leukemia in chronic phase with resistance or intolerance to imatinib. Leukemia. 2008:22(6):1200-1206.

16. Hughes TP, Lipton JH, Spector N, et al. Deep molecular responses achieved in patients with CML-CP who are switched to nilotinib after long-term imatinib. Blood. 2014:124(5):729-736.

17. Gambacorti-Passerini C, Brummendorf $\mathrm{TH}$, Kim DW, et al. Bosutinib efficacy and safety in chronic phase chronic myeloid leukemia after imatinib resistance or intolerance: Minimum 24-month follow-up. Am J Hematol. 2014:89(7):732-742.

18. Efficace F, Baccarani M, Breccia $M$, et al. Chronic fatigue is the most important fac tor limiting health-related quality of life of chronic myeloid leukemia patients treated with imatinib. Leukemia. 2013;27(7):15111519

19. Guerin A, Chen L, Ionescu-Ittu $R$, et al. Impact of low-grade adverse events on health-related quality of life in adult patients receiving imatinib or nilotinib for newly diagnosed Philadelphia chromosome positive chronic myelogenous eukemia in chronic phase. Curr Med Res Opin. 2014;30(11):2317-2328.

20. Flynn KE, Atallah E. Quality of life and long-term therapy in patients with chronic myeloid leukemia. Curr Hematol Malig Rep. 2016;11(2):80-85.

21. Hehlmann R, Lauseker M, Jung-Munkwitz $\mathrm{S}$, et al. Tolerability-adapted imatinib 800 $\mathrm{mg} / \mathrm{d}$ versus $400 \mathrm{mg} / \mathrm{d}$ versus $400 \mathrm{mg} / \mathrm{d}$ plus interferon-alpha in newly diagnosed chronic myeloid leukemia. J Clin Oncol. 2011;29(12):1634-1642.

22. Hasford J, Pfirrmann M, Hehlmann R, et al . A new prognostic score for survival of patients with chronic myeloid leukemia treated with interferon alfa. Writing Committee for the Collaborative CMI Prognostic Factors Project Group. J Nat Cancer Inst. 1998;90(11):850-858

23. Therneau TM, Grambsch PM. Modeling survival data: Extending the Cox model. New York: Springer, 2000.

24. Altmann DG, Lausen B, Sauerbrei W, Schumacher M. Dangers of using "Optimal" cutpoints in the evaluation of prognostic factors. J Natl Cancer Inst. 1994;86(11):829-835.

25. Davison AC, Hinkley DV. Bootstrap methods and their application. Cambridge: Cambridge University Press, 1997.

26. Silverman B. Density estimation for statistics and data analysis. London: Chapman and Hall, 1986

27. Saussele S, Richter J, Guilhot J, et al Discontinuation of tyrosine kinase inhibitor therapy in chronic myeloid leukaemia (EURO-SKI): a prespecified interim analysis of a prospective, multicentre, non-randomised, trial. Lancet Oncol. 2018:19(6):747-757.

28. Clark RE, Polydoros F, Apperley JF, et al De-escalation of tyrosine kinase inhibitor dose in patients with chronic myeloid leukaemia with stable major molecula response (DESTINY): an interim analysis of a non-randomised phase 2 trial. Lancet Haematol. 2017;4(7):e310-e316.

29. Fassoni AC, Baldow C, Roeder I Glauche I. Reduced tyrosine kinase inhibitor dose is predicted to be as effective as standard dose in chronic myeloid leukemia: A simulation study based on phase 3 trial data. Haematologica. 2018;103(11):1825-1834.

30. Hasford J, Baccarani M, Hoffmann V, et al. Predicting complete cytogenetic response and subsequent progression-free survival in 2060 patients with CML on imatinib treatment: the EUTOS score. Blood. 2011; 118(3):686-692.

31. Schutz C, Inselmann S, Sausslele S, et al. Expression of the CTLA-4 ligand CD86 on plasmacytoid dendritic cells $(\mathrm{pDC})$ predicts risk of disease recurrence after treatment discontinuation in CML. Leukemia. 2017; 31(4):829-836.

32. Inselmann $S$, Wang $Y$, Saussele $S$, et al Development, function and clinical significance of plasmacytoid dendritic cells in chronic myeloid leukemia. Cancer Res. 2018;78(21):6223-6234 